\title{
Follow-up after curative treatment for colorectal cancer: longitudinal evaluation of patient initiated follow-up in the first 12 months
}

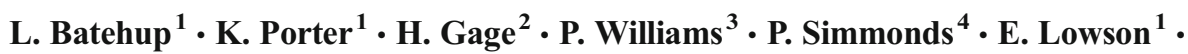

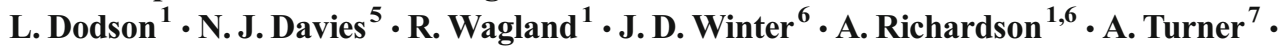 \\ J. L. Corner ${ }^{8}$
}

Received: 26 September 2016 / Accepted: 23 January 2017 /Published online: 14 February 2017

(C) The Author(s) 2017. This article is published with open access at Springerlink.com

\begin{abstract}
Purpose To compare patient-triggered follow-up (PTFU) for curatively treated colorectal cancer against traditional outpatient follow-up (OPFU).

Methods Questionnaires were mailed at four time points over one-year post-treatment to two prospectively-recruited cohorts: A, patients entering follow-up and receiving OPFU pre-implementation of PTFU; B, patients entering follow-up (FU) and receiving either OPFU (B1) or PTFU (B2) postimplementation of PTFU. Bi-variate tests were used to compare patient characteristics and outcomes eight months after entering follow-up (generic and cancer-specific quality of life (QoL), satisfaction). Regression analysis explored associations between follow-up model and outcomes. Resource implications and costs of models were compared.

Results Patients in Cohort B1 were significantly more likely to have received chemotherapy $(p<0.001)$, radiotherapy $(p<0.05)$, and reported poorer QoL $(p=0.001)$. Having a longstanding comorbid condition was the most important determinant of QoL
\end{abstract}

Electronic supplementary material The online version of this article (doi:10.1007/s00520-017-3595-x) contains supplementary material, which is available to authorized users.

L. Batehup

Lbatehup@soton.ac.uk

1 Health Sciences, Nightingale Building, University of Southampton, Highfield, Southampton, Hampshire SO17 1BJ, UK

2 School of Economics, University of Surrey, Guildford, Surrey GU2 7XH, UK

3 Department of Mathematics, University of Surrey, Guildford, Surrey GU2 7XH, UK $(p<0.001)$; model of care was not significant. Patients were satisfied with their follow-up care regardless of model. Health service costs were higher in PTFU over the first year Conclusions PTFU is acceptable to patients with colorectal cancer and can be considered to be a realistic alternative to OPFU for clinically suitable patients. The initial costs are higher due to provision of a self-management (SM) programme and remote surveillance. Further research is needed to establish long-term outcomes and costs.

Keywords Colorectal cancer $\cdot$ Aftercare $\cdot$ Follow-up $\cdot$ Patient triggered-follow-up $\cdot$ Remote surveillance

\section{Introduction}

Over 50\% of colorectal cancer (CRC) patients survive for five years or more [1]. With an estimated 250,000 people in the

4 Cancer Research UK, Clinical Research Unit, University of Southampton, Tremona Road, Southampton, Hampshire SO16 6YD, UK

5 Health Psychology Consultancy Ltd., Staffordshire, UK

6 University Hospital Southampton NHS Foundation Trust, Tremona Road, Southampton, Hampshire SO16 6YD, UK

7 Centre for Technology Enabled Health Research, Faculty of Health and Life Sciences, Coventry University, Priory Street, Coventry CV1 $5 \mathrm{FB}, \mathrm{UK}$

8 The University of Nottingham, Executive Office, Trent Building, University Park, Nottingham NG7 2RD, UK 
UK having a diagnosis of CRC, pressure is evident on followup services through competing demands of new patient management, alongside growing numbers of survivors [2]. Traditionally, following treatment, patients enter routine outpatient follow-up (OPFU) delivered by medical clinicians, and more recently by clinical nurse specialists (CNS) [3-6], for surveillance to detect treatable recurrence and manage ongoing symptoms [7, 8]. Although intensive follow-up investigations to detect recurrence after curative resection offer a survival benefit for CRC, clinical examination has been shown to be of limited value $[8,9]$.

Alternatives to face-to-face FU have been evaluated for breast cancer, including primary care strategies [10], nurseled follow-up [11], and patient-triggered follow-up (PTFU) [12]. For CRC, nurse-led clinics and telephone follow-up [3-6] have been shown to be effective for delivering holistic care and detecting treatable recurrence, alongside consultant care. It is untenable in the long-term, however, to substitute CNS's for medical staff in nurse-led clinic or telephone follow-up; the CNS workforce is not expanding at a sufficient rate to keep pace with rising need [13]. PTFU offers a potential model to meet the needs of growing numbers of CRC survivors [14], linking patient-initiated contact with education to self-manage [15], and coordination by specialist colorectal CNS's. A service improvement project was undertaken with the colorectal clinical team at a cancer treatment centre in Southern England to implement PTFU for curatively treated CRC patients, utilising a remote surveillance system [14]. As PTFU is a novel approach to FU for CRC, a service evaluation was undertaken.

In January 2012, after approval by hospital governance, a PTFU remote surveillance protocol [16] was introduced (Details in Online Resource 1). Patients enter PTFU when ongoing symptoms are resolved, either directly after surgical resection or following time spent in OPFU. They are invited to attend a 4-h self-management (SM) workshop, developed by SM researchers at Coventry University, and run by a CNS and $\mathrm{CRC}$ survivor. Thereafter no further routine $\mathrm{FU}$ appointments are arranged. Standard OPFU is available for patients who require ongoing symptom management, and for those on clinical trials requiring tailored follow up management plans. Details of the care pathway for patients accessing PTFU is in Online Resource 2. Diagnostic tests for PTFU patients are coordinated by a colorectal CNS and administrator according to the agreed surveillance protocol (Online Resource 1) using a customised IT system. Results are reviewed by the CNS, and when normal, a letter was sent to the patient. Abnormal results are reviewed at the multidisciplinary meeting and further action taken as appropriate.

The evaluation was conducted over the period following end of acute treatment and entering survivorship when those in FU care can have a range of physiological, psychosocial and functional needs, and individual patients differ in their health status and response to cancer and its treatment [17]. Patient-reported quality of life (QoL) outcomes and satisfaction with care were compared before and after the implementation of PTFU. Patients were followed for 12 months after ending treatment. Detection of recurrence and survival are not being addressed. Costs and health service utilisation were compared.

\section{Materials and methods}

\section{Study participants}

Two cohorts of patients entering follow-up were recruited prospectively. Cohort A entered OPFU before the service change, between April and December 2011; Cohort B entered follow-up after the implementation of PTFU, between January 2012 and August 2013. Depending on their clinical status, patients in Cohort B could be enrolled in either OPFU (for ongoing symptom management) or PTFU. Patients were identified through hospital records and clinician referral. Eligibility criteria were: completion of all treatment with curative intent for CRC; absence of a second cancer diagnosed during treatment; age 18 years or over; no dementia, severe memory loss, or learning disability preventing questionnaire completion. Written consent was obtained.

\section{Data collection}

Data were collected by self-report using structured questionnaires that were mailed at four time points: on completion of final curative treatment (baseline T0), 4 months later (T1), 8 months later (T2), 12 months later (T3). Reminders were sent after two, four and six weeks to non-respondents. Hospital records were used to check patient survival status prior to mailings. Socio-demographic data and information about long-term conditions (LTCs) were gathered at baseline. Postcode was used to derive the Index of Multiple Deprivation (IMD), a government measure reflecting income, employment, housing and other social indicators for local areas [18]. With consent, clinical records were accessed to gather details of time since diagnosis, all types of treatments received, date of entering FU, timing of recurrence or metastatic disease, and, for PTFU patients, attendance at a SM workshop (yes/no).

\section{Outcome measures}

Generic health related quality of life (HRQoL) was measured with EQ-5D-5 L. Scores for each of five domains (mobility, self-care, usual activities, pain, anxiety / depression) are combined and converted into a summary utility index; a maximum score of 1 indicating "full health" (no problems on any domain). Participants also completed the EQ-5D visual analogue scale (range $0-100$ best possible health) $[19,20]$. Cancer- 
specific QoL was measured using the Functional Assessment of Cancer Therapy: General (FACT-G) yielding four functional subscales (physical, social, emotional, functional wellbeing); higher scores indicate better functioning. [21], and FACT-C Colorectal Cancer Subscale (CCS) higher score indicates better functioning [22].

A tool was designed for this study to assess patient experience of follow-up care, with 8 items generated from a review of follow-up evaluations, covering: reassurance, who to contact with problems, comfort about contacting health professionals (HPs) with problems, feelings of isolation, thoroughness of care, ability to ask questions, sufficient time from HPs, involvement in care decisions. [11, 12, 23]. Responses were scored 0 to 100 (best). Respondents also rated if care was acceptable (yes/no/unsure); met their expectations (exceeded/met/fell short); and their perception of service quality (excellent/very good/good/fair/poor).

\section{Sample size calculation}

The primary outcome was the FACT-G. Other related studies have observed pertinent survivorship issues following completing treatment for CRC, suggest a standard deviation (SD) of 14.6 [24] for FACT-G within the first year after surgery. In order to detect an underlying difference of 10 points in FACT$\mathrm{G}$ whilst making no assumption about statistically significant difference direction, using a two-sided test with size $=5 \%$ and power $=80 \%$, required at least 35 patients in each follow-up regime (the pre and post change cohorts). With six months planned for recruitment for Cohort A (OPFU), a sample of 35 was considered achievable, even allowing for up to $40 \%$ dropout [25-27]. However, in order to conduct a valid comparison between OPFU and PTFU, a larger cohort was deemed necessary for Cohort B because clinicians would not enrol all patients directly into PTFU. Assuming at least one in three patients is in PTFU by T2, and a dropout rate of not more than $40 \%$ by T2, at least 175 patients needed to be recruited to Cohort B to acquire at least 35 PTFU patients at T2.

\section{Data analyses}

Baseline characteristics of responders and non-responders were compared. Patients in the post-change B cohort, who started follow-up in PTFU or had been transferred by clinicians to PTFU by T2, were assigned to group B2 for analysis. Patients remaining in OPFU (B) at T2 were assigned to group B1. Summary statistics (numbers, proportions, means, and standard deviations) were calculated for all variables at baseline and $\mathrm{T} 2$, and comparisons between follow-up regimes were conducted using appropriate statistical tests (chi-square for categorical variables, Fisher's exact test for dichotomous variables when an expected cell count of $<5$ was encountered, unpaired t-test for continuous variables, Mann-Whitney U test for ordinal variables). Forward linear regression modelling was undertaken to explore the effect on patient outcomes (EQ-5D utility index, FACT-G, general QoL score, additional colorectal cancer concerns score (CCS)) after different exposure lengths to PTFU while controlling for demographic factors, co-morbid conditions, and clinical management.

\section{Economic evaluation}

The NHS perspective was primarily adopted, comparing costs of OPFU with PTFU in British Pounds, 2013. Two factors were considered: impact on direct costs, reflecting replacement of clinic follow-up visits in OPFU, by selfmanagement in PTFU; unscheduled service use by patients, to explore if removal of outpatient clinic access was associated with increased visits to other health professionals. Resources involved in delivering OPFU and PTFU were obtained from clinic protocols and health professionals, covering the first year of follow-up. Costs were attributed to staff resources using validated national scales [28], and costs of facilities and other physical resources based on actual expenditures. To measure service utilisation, patients were asked at each time point to retrospectively self-report health service use since completing the last questionnaire, using a modified Client Service Receipt Inventory [29]. To minimise confounding, since some patients moved from OPFU to PTFU between $\mathrm{T} 0$ and $\mathrm{T} 2$, the analysis period was confined to between $\mathrm{T} 1$ and T2. Paired group comparison was undertaken (A vs. B; B1 vs. B2; A vs. B2), covering utilisation of the most commonly used services. To assess personal costs, information was requested on travel to clinic appointments, whether accompanied by others, and time lost from work. Travelling distance to the hospital was calculated using postcodes.

\section{Ethical considerations}

The National Research Ethics Service judged this to be a service evaluation. Governance approval was obtained from the Trust Research and Development Department; the study was conducted according to the ethical principles of informed consent and assurance of confidentiality. Storage and processing of data conformed to the Data Protection Act 2000.

\section{Results}

\section{Recruitment and retention}

Of 124 patients sent baseline questionnaires in Cohort A, $75(60.5 \%)$ were returned in a timely manner; 176 of 239 (73.6\%) were returned in Cohort B. Not all patients responded at subsequent time periods; $53(70.7 \%)$ and $79(44.9 \%)$ responses were analysable at $\mathrm{T} 2$ respectively 
Fig. 1 Flow chart of recruitment and retention of patients in Cohort A

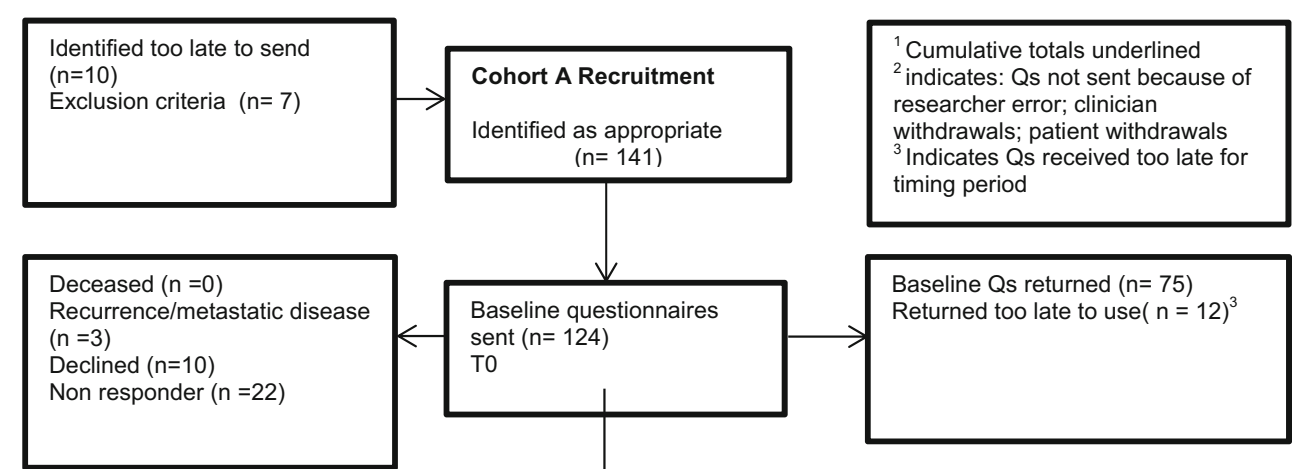

Developed recurrence or metastatic disease $(n=2)(5)^{1}$

Deceased $(n=2)$

Recurrence/metastatic

disease $(n=1)$

Declined $(n=4)$

Not $\operatorname{sent}(n=3)^{2}$

(2)

$\frac{(6)^{1}}{(14)^{1}}$

$(14$

.

Developed recurrence or metastatic disease $(n=2)$

\section{(8)}

8 month Qs returned $(n=53)$

Returned too late to use $(n=6)^{3}$

Non responder $(n=6)$

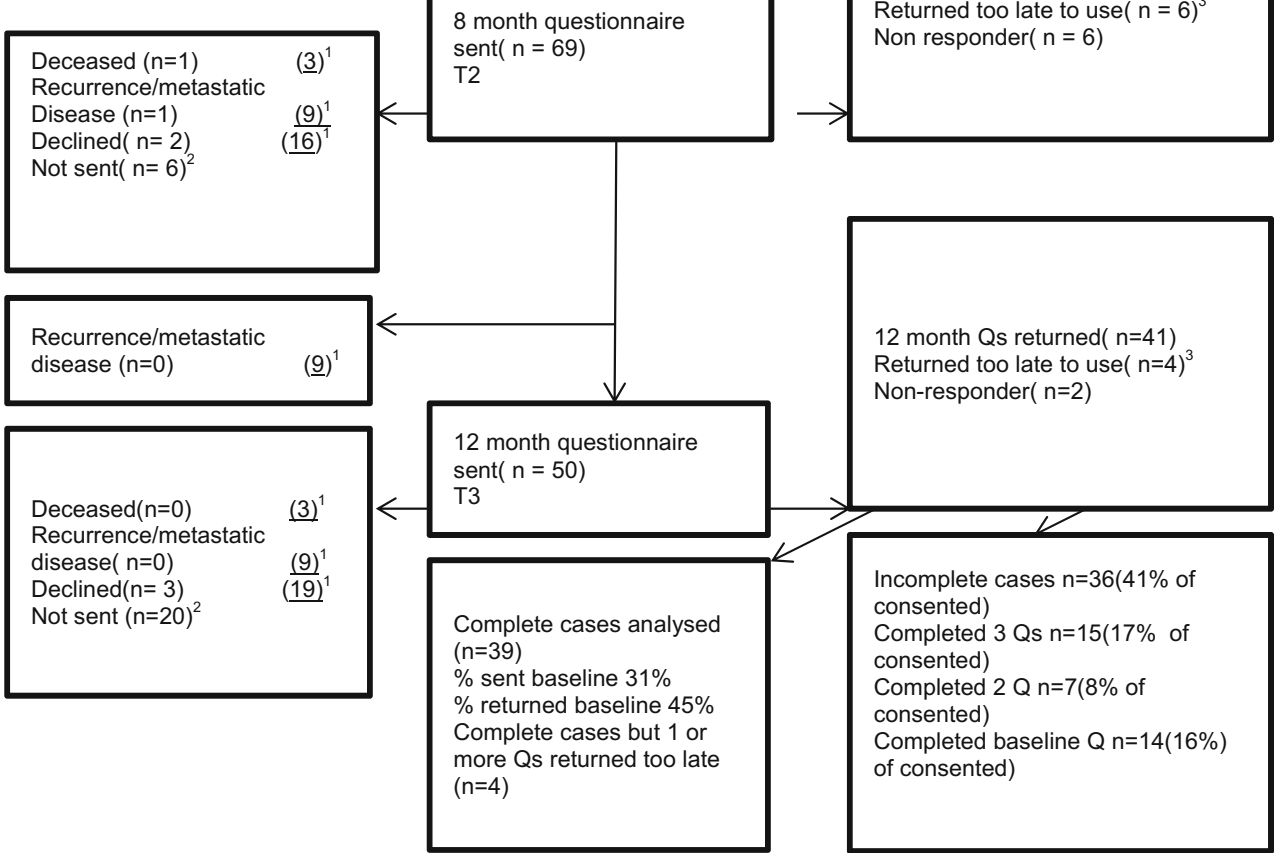

(Figs. 1 and 2). Of the 176 patients recruited into the second phase of the study, there were 31 in PTFU at T0; 34 had crossed over by T1, a further 14 had crossed over by $\mathrm{T} 2$, and a further 5 at T3.

Comparison of the 251 responders with 112 nonresponders at baseline revealed no significant difference in age, sex, or deprivation. Comparison of the characteristics of 132 participants at T2 against the remaining 119 baseline patients from whom a T2 questionnaire was not obtained, showed that those not in the analysis at T2 were more likely to have a recurrence or metastatic disease (data not shown). 
Fig. 2 Flow chart of recruitment and retention of patients in Cohort B

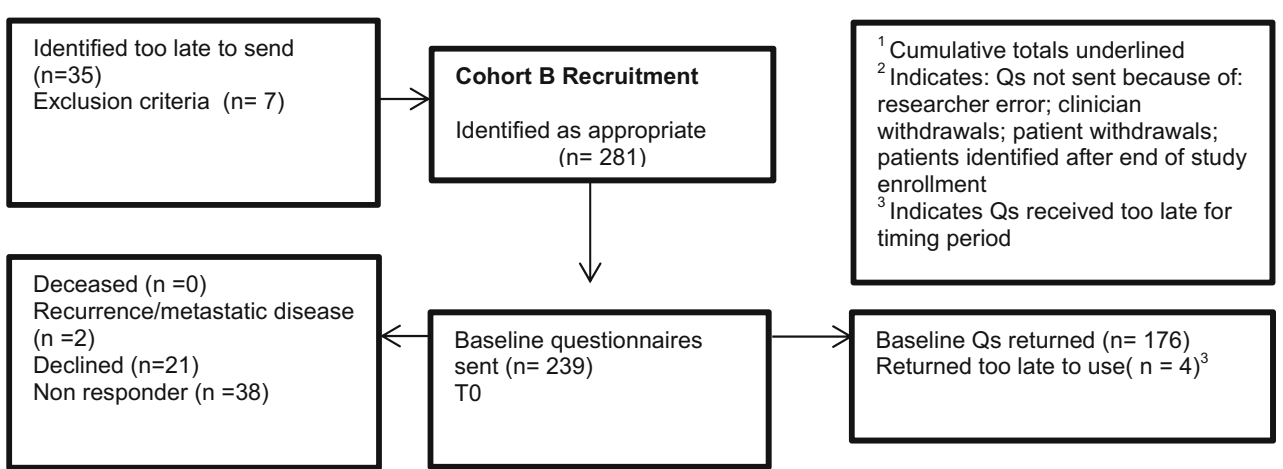

Developed

recurrence/metastatic disease $(n=10)$

$(12)^{1}$

Deceased $(n=3)$

Recurrence/metastatic

disease $(n=4)$

$\operatorname{Declined}(\mathrm{n}=4)$

Not sent $(n=33)^{2}$

$(3)^{1}$

$(16)^{1}$

$(25)^{1}$
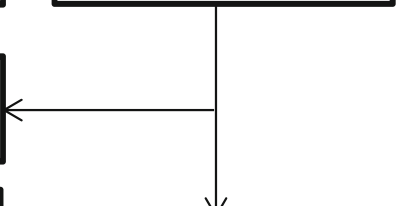

$\underline{(25)}$

$(n=138)$

month $Q$ s returned $(n=118)$

Returned too late to use $(n=3)^{3}$

Non responder $(n=6)$
Developed recurrence or metastatic disease $(n=2)$ $(18)^{1}$
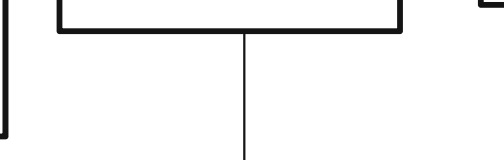

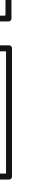

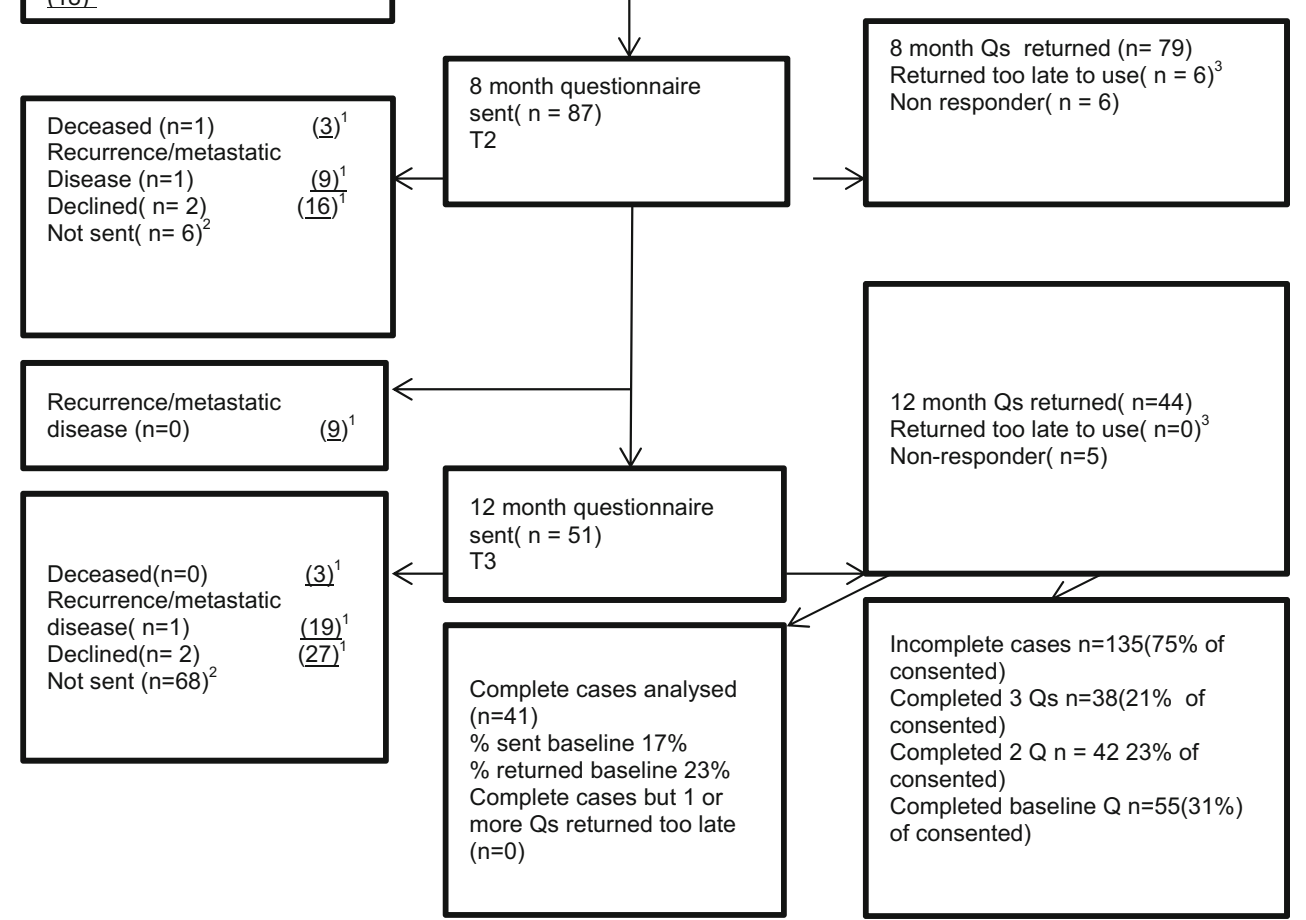

\section{Baseline comparison of groups}

Comparison of Cohorts $\mathrm{A}(n=75)$ and $\mathrm{B}(n=176)$ at baseline showed a significantly higher proportion of Cohort B patients had received chemotherapy, and a significantly higher proportion of Cohort A patients reported having arthritis. The groups did not differ on socio-demographic characteristics (mean age 72 years, $40 \%$ women) or outcome measures (Table 1 ).

At baseline, most of the 176 patients in Cohort B were still in OPFU (145 vs. 31 in PTFU). No significant differences were found in socio-demographic characteristics of patients in B1 and B2. Patients retained in OPFU (B1) compared to 
those selected for PTFU (B2) were more likely to have received chemotherapy, radiotherapy, and multiple treatments. They reported lower self-rated health and physical wellbeing, and worse CCS scores (Table 1)

\section{Outcomes at $\mathrm{T} 2$}

QoL outcomes were not significantly different between Cohorts $\mathrm{A}$ and $\mathrm{B}$ at $\mathrm{T} 2$. Compared to patients in B1 (OPFU), those in B2 (PTFU) had significantly better HRQoL and CCS scores (Table 2). Regression modelling identified a high number of LTCs as the dominant factor associated with adverse HRQoL outcomes; this was offset by a positive effect for heart disease(HD). Chemotherapy negatively affected CCS scores. Patients in work reported worse CCS scores. Time spent in PTFU was not significantly associated with any outcome. The models explained less than $20 \%$ of the variation (Table 3 ).

There were no significant differences in experience of follow-up care between OPFU (A and B1) and PTFU (B2) with respect to reassurance, access to specialist support, ability to ask questions, time spent with doctors/nurses, and involvement in decision-making. More patients in PTFU (36/37; 97.3\%) found their follow-up to be acceptable (vs. not/unsure) than patients in OPFU $(24 / 32 ; 75 \%)(p=0.010)$. There were no significant differences between groups regarding quality of care or the extent to which it met expectations; most reported high satisfaction (Table 4).

\section{Costs and service utilisation}

Detailed analysis of the patient pathways under OPFU and PTFU showed that PTFU was up to $£ 142.24$ per patient more expensive than OPFU in the first year. Savings in outpatient appointments in PTFU were outweighed by the costs of the self- management workshop and remote surveillance (Online Resource 3 Table, of Resources and Costs). No significant differences were found between utilisation of community and hospital services for any group comparison (data not shown), except GP visits were higher for OPFU patients than PTFU patients (1.84 vs. 1.08 monthly visits, $p=0.024)$. Most patients (76.9\%) reported travelling to clinic by car, the mean (SD) round trip distance between home postcodes and the hospital being 18.73 (12.82) miles. Applying the NHS mileage reimbursement rate (2014) of $50.5 \mathrm{p}$ per mile, a move to PTFU would save $£ 28.38$ per patient in the first year (assuming OPFU involves four clinic visits vs one in PTFU). The majority ( $87.9 \%$ ) were mostly or sometimes accompanied to clinics so additional savings might arise for companions $(22.3 \%)$ taking time off work.

\section{Discussion}

This study makes an important contribution to our understanding of the impact of introducing PTFU for CRC survivors. When the new model was launched, clinicians' choices of follow-up model were influenced by patients' disease and treatment characteristics, health outcomes and symptom burden. When PTFU was introduced, almost one half (48\%) of patients were enrolled in PTFU within 8 months of entering follow-up (mean time from final treatment to entering PTFU of 3.75 months). This pattern is similar to findings from three other NHS hospitals piloting stratified follow-up for colorectal patients, where $40-45 \%$ were judged able to self-manage 4 6 months' post-treatment or reversal of stoma [30], and a study of remote surveillance for post-resection patients, which enrolled 50\% in the new model [31]. As a new practice model early in its implementation, the role of clinician attitude and culture may have limited PTFU enrolment in our study, requiring time to evolve so that trust with the new system can be established [10]. Patient choice may also have influenced selection of follow-up model [32].

Since the evaluation covered the early period post-treatment, the majority of the PTFU group were patients postsurgical resection who had not undergone chemotherapy. Patients who were not enrolled in PTFU were found to have poorer HRQoL and cancer specific QoL, which may explain why these patients made more visits to their general practitioner than did PTFU patients. It is clear that treatment factors are important predictors of patient outcomes. For patients in this study, chemotherapy was predictive of poorer cancer specific QoL and colorectal concerns, a finding consistent with other studies investigating QoL in CRC patients [33].

Eight months after the end of treatment, having one or more LTCs was the most dominant negative influence on HRQoL, cancer specific QoL, and colorectal concerns. This finding is consistent with other studies, and accounts for activity limitations, and participation restrictions (in work, daily activities) [25-27]. The importance of bowel symptoms such as diarrhoea and faecal control and QoL have been reported before $[27,34]$, and coping with these symptoms in the workplace probably accounts for the negative association of colorectal concerns with being in work. The positive effect on colorectal concerns by HD may be related to behaviours learned to selfmanage heart disease as a LTC, being used to cope with the adverse effects of CRC treatment on bowel control. A proportion of participants with HD will have attended a cardiac rehabilitation programme, having benefits, which equipped participants to deal with another serious condition. [35]

Follow-up model was not a significant influence on outcomes in this study, possibly because the FU period was too short to make a significant impact on patients. Findings by Siddika et al. [31] indicate patient satisfaction with remote surveillance is high in years 3 and 4 of follow-up. Few other 
Table 1 Socio-demographic, clinical characteristics, treatment, and patient reported outcomes according to model of follow-up at T0: Cohort A vs Cohort B, and Cohort B1 vs Cohort B2

\begin{tabular}{|c|c|c|c|c|c|c|c|}
\hline \multirow[b]{2}{*}{ Characteristics } & & \multicolumn{2}{|l|}{ Cohort } & \multirow{2}{*}{$\begin{array}{l}\text { Difference } \\
P \text {-value }\end{array}$} & \multicolumn{2}{|l|}{ Cohort } & \multirow{2}{*}{$\begin{array}{l}\text { Difference } \\
P \text {-value }\end{array}$} \\
\hline & & $\mathrm{A}(n=75)$ & $\mathrm{B}(n=176)$ & & $\mathrm{B} 1(n=92)$ & $\mathrm{B} 2(n=84)$ & \\
\hline \multirow[t]{4}{*}{ Socio-demographic } & Age mean(SD) & $72.9(8.7)$ & $71.6(10.6)$ & $0.340^{\mathrm{a}}$ & $71.1(10.4)$ & $72.1(10.8)$ & $0.524^{\mathrm{a}}$ \\
\hline & Gender $=$ Female $(\%)$ & $27(36)$ & $74(42)$ & $0.371^{\mathrm{b}}$ & $38(41)$ & $36(43)$ & $0.835^{\mathrm{b}}$ \\
\hline & Ethnicity = White $(\%)$ & $70(97)$ & 171(99) & $0.156^{\mathrm{b}}$ & 89(99) & $82(100)$ & $1.000^{\mathrm{b}}$ \\
\hline & Domestic status $=$ Live alone $(\%)$ & $21(30)$ & $38(22)$ & $0.347^{\mathrm{b}}$ & $14(16)$ & $24(30)$ & $0.155^{\mathrm{b}}$ \\
\hline \multirow{4}{*}{$\begin{array}{l}\text { Education, Highest } \\
\text { qualification }\end{array}$} & No qualifications (\%) & $25(42)$ & $56(36)$ & $0.658^{\mathrm{c}}$ & $31(39)$ & $25(32)$ & $0.296^{\mathrm{c}}$ \\
\hline & GCE/O Level (\%) & $8(13)$ & $25(16)$ & & $14(18)$ & $11(14)$ & \\
\hline & A-Level $(\%)$ & $4(7)$ & $14(9)$ & & $5(6)$ & $9(12)$ & \\
\hline & Vocational qualification & $15(25)$ & $42(27)$ & & $22(28)$ & $20(26)$ & \\
\hline \multirow[t]{6}{*}{ Working status } & Unable to work $(\%)$ & $6(9)$ & $11(6)$ & $0.275^{\mathrm{b}}$ & $7(8)$ & $4(5)$ & $0.554^{\mathrm{b}}$ \\
\hline & Able to work (\%) & $7(10)$ & $31(18)$ & & $14(16)$ & $17(21)$ & \\
\hline & N/A Retired $(\%)$ & $56(81)$ & $128(75)$ & & $67(76)$ & $61(74)$ & \\
\hline & Hours worked last week (SD) & $20.55(16.07)$ & $25.05(15.75)$ & $0.560^{\mathrm{a}}$ & $21.08(15.52)$ & $28.28(15.67)$ & $0.227^{\mathrm{a}}$ \\
\hline & Hours normally worked per week mean(SD) & $26(13.38)$ & $30.19(13.2)$ & $0.492^{\mathrm{a}}$ & $27.05(13.44)$ & $32.5(12.99)$ & $0.307^{\mathrm{a}}$ \\
\hline & Days sick leave in past 4 weeks mean (SD) & $2(4.47)$ & $3.76(7.75)$ & $0.630^{\mathrm{a}}$ & $5.1(7.64)$ & $2.87(7.95)$ & $0.492^{\mathrm{a}}$ \\
\hline \multirow[t]{10}{*}{ Clinical } & Months, first diagnosis to T0 mean (SD) & $7.6(4.66)$ & $6.51(3.72)$ & $0.075^{\mathrm{a}}$ & $7.81(4.11)$ & $5.09(2.59)$ & $<0.001^{\mathrm{a}}$ \\
\hline & Months, end of last treatment to $\mathrm{T} 0$ mean(SD) & $3.08(2.54)$ & $2.22(1.69)$ & $0.010^{\mathrm{a}}$ & $2.53(1.81)$ & $1.9(1.5)$ & $0.015^{\mathrm{a}}$ \\
\hline & $\begin{array}{l}\text { Months, end of last treatment to } \\
\text { PTFU mean(SD) }\end{array}$ & - & - & - & - & $3.75(3.61)$ & - \\
\hline & Number of LTCs mean (SD) & $1.1(1.19)$ & $0.95(1.07)$ & $0.348^{\mathrm{a}}$ & $1.02(1.14)$ & $0.88(0.99)$ & $0.372^{\mathrm{a}}$ \\
\hline & Diabetes $(\%)$ & $10(14.3)$ & $25(15)$ & $0.892^{\mathrm{b}}$ & $15(17.4)$ & $10(12.3)$ & $0.356^{\mathrm{b}}$ \\
\hline & Heart Disease (\%) & $7(10)$ & $21(12.6)$ & $0.575^{\mathrm{b}}$ & $10(11.6)$ & 11(13.6) & $0.704^{\mathrm{b}}$ \\
\hline & $\operatorname{COPD}(\%)$ & $2(2.9)$ & $6(3.6)$ & $1.000^{\mathrm{d}}$ & $3(3.5)$ & $3(3.7)$ & $1.000^{\mathrm{d}}$ \\
\hline & Arthritis (\%) & $17(24.3)$ & $23(13.8)$ & $0.049^{\mathrm{b}}$ & $10(11.6)$ & $13(16)$ & $0.407^{\mathrm{b}}$ \\
\hline & Depression (\%) & $3(4.3)$ & $6(3.6)$ & $0.726^{\mathrm{d}}$ & $3(3.5)$ & $3(3.7)$ & $1.000^{\mathrm{d}}$ \\
\hline & High blood pressure $(\%)$ & $27(38.6)$ & $48(28.7)$ & $0.138^{\mathrm{b}}$ & $30(34.9)$ & $18(22.2)$ & $0.071^{\mathrm{b}}$ \\
\hline \multirow[t]{4}{*}{ Last treatment received } & Surgery $(\%)$ & $59(84)$ & $117(70)$ & $0.114^{\mathrm{b}}$ & $47(53)$ & $70(90)$ & $<0.001^{\mathrm{b}}$ \\
\hline & Chemotherapy (\%) & $10(14)$ & $43(26)$ & & $36(40)$ & $7(9)$ & \\
\hline & Radiotherapy (\%) & 1(1) & $3(2)$ & & $3(3)$ & $0(0)$ & \\
\hline & Other $(\%)$ & $0(0)$ & $4(2)$ & & $2(2)$ & $2(3)$ & \\
\hline \multirow[t]{6}{*}{ Additive treatment } & Surgery only $(\%)$ & $52(69)$ & $107(61)$ & $0.024^{\mathrm{b}}$ & $40(43)$ & $67(80)$ & $<0.001^{\mathrm{b}}$ \\
\hline & Surgery + Chemotherapy $(\%)$ & $8(11)$ & $48(27)$ & & $36(39)$ & $12(14)$ & \\
\hline & Surgery + Chemotherapy +Radiotherapy $(\%)$ & $10(13)$ & $16(9)$ & & $12(13)$ & $4(5)$ & \\
\hline & Surgery + Radiotherapy $(\%)$ & $3(4)$ & $5(3)$ & & $4(4)$ & $1(1)$ & \\
\hline & Surgery + Microwave Ablation (\%) & $1(1)$ & $0(0)$ & & $(0)$ & $(0)$ & \\
\hline & $\begin{array}{l}\text { Surgery }+ \text { Chemotherapy }+ \\
\quad \text { Microwave Ablation }(\%)\end{array}$ & $1(1)$ & $0(0)$ & & $(0)$ & $(0)$ & \\
\hline \multirow[t]{3}{*}{ Previous cancer diagnosis } & Yes $(\%)$ & $8(11)$ & $14(8)$ & $0.487^{\mathrm{b}}$ & $9(10)$ & $5(6)$ & $0.348^{\mathrm{b}}$ \\
\hline & No $(\%)$ & $67(89)$ & $162(92)$ & & $83(90)$ & $79(94)$ & \\
\hline & Metastatic disease removed prior to $\mathrm{T} 0: \mathrm{No}(\%)$ & $72(96)$ & 171(97) & $0.699^{\mathrm{d}}$ & $87(95)$ & $84(100)$ & $0.060^{\mathrm{d}}$ \\
\hline \multirow[t]{8}{*}{$\begin{array}{l}\text { Patient Reported } \\
\text { Outcome Measures }\end{array}$} & $\begin{array}{l}\text { EQ5D-5 L index, mean(SD) } \\
\quad[\text { worst }-0.594, \text { best } 1]\end{array}$ & $0.8(0.21)$ & $0.82(0.17)$ & $0.480^{\mathrm{a}}$ & $0.79(0.16)$ & $0.86(0.17)$ & $0.010^{\mathrm{a}}$ \\
\hline & EQ5D-5 L VAS mean(SD) [worst 0-100] & 76.57(21.16) & $77.35(16.95)$ & $0.758^{\mathrm{a}}$ & $73.5(18.55)$ & $81.73(13.79)$ & $0.001^{\mathrm{a}}$ \\
\hline & FACT:PWB mean(SD) [worst 0 , best 28 ] & $24.05(4.9)$ & 24.7(3.74) & $0.307^{\mathrm{a}}$ & $23.91(4.26)$ & $25.59(2.82)$ & $0.003^{\mathrm{a}}$ \\
\hline & FACT:SWB mean(SD) [worst 0, best 28] & $22.97(5.41)$ & $22.6(6.13)$ & $0.662^{\mathrm{a}}$ & $23.16(4.98)$ & $21.99(7.15)$ & $0.224^{\mathrm{a}}$ \\
\hline & FACT:EWB mean(SD) [worst 0 , best 24$]$ & $20.68(3.96)$ & $20.52(3.28)$ & $0.744^{\mathrm{a}}$ & $20.23(3.05)$ & $20.82(3.5)$ & $0.246^{\mathrm{a}}$ \\
\hline & FACT:FWB mean(SD) [worst 0, best 28] & $20.52(8.02)$ & $20.63(6.65)$ & $0.705^{\mathrm{a}}$ & $19.92(6.34)$ & $21.65(6.88)$ & $0.060^{\mathrm{a}}$ \\
\hline & FACT: CRCs mean(SD) [worst 0 , best 28 ] & $21.38(5.12)$ & $22.06(4.55)$ & $0.301^{\mathrm{a}}$ & $20.98(5.06)$ & $23.23(3.62)$ & $0.001^{\mathrm{a}}$ \\
\hline & FACT-G total mean(SD) [0 worst, best 108$]$ & $89.81(16.35)$ & $89.08(14.15)$ & $0.736^{\mathrm{a}}$ & $88.22(12.84)$ & $90.01(15.48)$ & $0.429^{\mathrm{a}}$ \\
\hline
\end{tabular}

Cohort A: Pre-change outpatient follow-up; Cohort B: Post-change outpatient follow-up + PTFU;

Cohort B1: Post-change outpatient follow-up only; Cohort B2: Post-change PTFU only

${ }^{a}$ Unpaired $t$ test

${ }^{\mathrm{b}}$ Chi-square test

${ }^{\mathrm{c}}$ Mann-Whitney U test

${ }^{\mathrm{d}}$ Fisher's Exact test

Abbreviations: GCE/O level = General Certificate of Education, Ordinary level; A-level = Advanced level; PTFU = patient-triggered follow-up; LTCs = Long term conditions; COPD = Chronic obstructive pulmonary disease; EQ5D-5 L = Euro-Qol Group index; VAS = visual analogue scale; $\mathrm{FACT}=$ Functional Assessment of Cancer Treatment; $\mathrm{PWB}=$ physical wellbeing subscale; SWB = social wellbeing; EWB = emotional wellbeing; FWB = functional wellbeing; $\mathrm{CRCs}=$ additional colorectal cancer concerns; FACT-G $=$ Functional Assessment of Cancer Therapy- General Total QoL score 
Table 2 Patient reported outcomes according to model of follow-up at T2:Cohort A vs Cohort B, and Cohort B1 vs Cohort B2

\begin{tabular}{|c|c|c|c|c|c|c|c|}
\hline \multirow{2}{*}{ Characteristics } & & \multicolumn{2}{|l|}{ Cohort } & \multirow{2}{*}{$\begin{array}{l}\text { Difference } \\
P \text {-value }\end{array}$} & \multicolumn{2}{|l|}{ Cohort } & \multirow{2}{*}{$\begin{array}{l}\text { Difference } \\
P \text {-value }\end{array}$} \\
\hline & & $\mathrm{A}(n=53)$ & $\mathrm{B}(n=79)$ & & $\mathrm{B} 1(n=38)$ & $\mathrm{B} 2(n=41)$ & \\
\hline \multirow[t]{4}{*}{ Socio-demographic/Clinical } & Age at T2 mean(SD) & $72.9(8.7)$ & $71.6(10.6)$ & $0.340^{\mathrm{a}}$ & $71.1(10.4)$ & $72.1(10.8)$ & $0.524^{\mathrm{a}}$ \\
\hline & $\begin{array}{l}\text { Months from first diagnosis } \\
\text { to T2 mean (SD) }\end{array}$ & $15.05(4.31)$ & $14.21(3.24)$ & $0.201^{\mathrm{a}}$ & $15.55(3.6)$ & $12.96(2.26)$ & $0.003^{\mathrm{a}}$ \\
\hline & $\begin{array}{l}\text { Months from end of last } \\
\text { treatment to T2 mean(SD) }\end{array}$ & $11.08(2.45)$ & $10.47(1.77)$ & $0.128^{\mathrm{a}}$ & $10.68(1.81)$ & $10.29(1.73)$ & $0.333^{\mathrm{a}}$ \\
\hline & $\begin{array}{l}\text { Months from end of last } \\
\text { treatment to PTFU } \\
\text { mean(SD) }\end{array}$ & $\begin{array}{c}\text { Not } \\
\text { applicable }\end{array}$ & $6.28(4.10)$ & $\begin{array}{c}\text { Not } \\
\text { applicable }\end{array}$ & $15.52(2.42)$ & $5.38(2.94)$ & $<0.001^{\mathrm{a}}$ \\
\hline \multirow[t]{6}{*}{ Additive Treatment } & Surgery only $(\%)$ & $38(72)$ & $49(62)$ & $0.123^{\mathrm{b}}$ & $16(42)$ & $33(80)$ & $0.004^{\mathrm{b}}$ \\
\hline & Surgery + Chemo $(\%)$ & $4(8)$ & $19(24)$ & & $14(37$ & $5(12)$ & \\
\hline & Surgery + Chemo +RT $(\%)$ & $6(11)$ & $8(10)$ & & $5(13)$ & $3(7)$ & \\
\hline & Surgery + RT (\%) & $3(6)$ & $3(4)$ & & $3(8)$ & $0(0)$ & \\
\hline & Surgery + MA (\%) & $1(2)$ & $0(0)$ & & $0(0)$ & $0(0)$ & \\
\hline & Surgery + Chemo + MA $(\%)$ & $1(2)$ & $0(0)$ & & $0(0)$ & $0(0)$ & \\
\hline \multirow[t]{8}{*}{ Patient reported outcomes } & $\begin{array}{l}\text { EQ5D-5 L health score } \\
\text { mean }(\mathrm{SD})\end{array}$ & $0.81(0.23)$ & $0.83(0.17)$ & $0.480^{\mathrm{a}}$ & $0.79(0.16)$ & $0.87(0.15)$ & $0.033^{\mathrm{a}}$ \\
\hline & EQ5D-5 L VAS mean(SD) & $81.58(18.45)$ & $78.5(15.56)$ & $0.302^{\mathrm{a}}$ & $73.57(16.66)$ & $83.07(13.07)$ & $0.006^{\mathrm{a}}$ \\
\hline & FACT:PWB mean(SD) & $24.19(5.6)$ & $25.31(3.7)$ & $0.199^{\mathrm{a}}$ & $24.56(3.96)$ & $26.05(2.19)$ & $0.043^{\mathrm{a}}$ \\
\hline & FACT:SWB mean(SD) & $22.92(4.65)$ & $21.7(6.35)$ & $0.227^{\mathrm{a}}$ & $21.64(6.53)$ & $21.82(6.25)$ & $0.899^{\mathrm{a}}$ \\
\hline & FACT:EWB mean(SD) & 20.94(3.39) & $20.28(3.13)$ & $0.269^{\mathrm{a}}$ & $19.82(3.23)$ & $20.73(2.99)$ & $0.205^{\mathrm{a}}$ \\
\hline & FACT:FWB mean(SD) & $21.38(6.92)$ & $20.97(5.7)$ & $0.715^{\mathrm{a}}$ & $19.46(5.72)$ & $22.4(5.37)$ & $0.022^{\mathrm{a}}$ \\
\hline & FACT: CRCs mean(SD) & $22.2(4.89)$ & $22.66(3.51)$ & $0.566^{\mathrm{a}}$ & $21.77(3.75)$ & $23.55(3.05)$ & $0.026^{\mathrm{a}}$ \\
\hline & FACT-G total mean(SD) & $91.98(15.01)$ & $88.31(13.3)$ & $0.163^{\mathrm{a}}$ & $85.48(13.58)$ & $91.15(12.56)$ & $0.063^{\mathrm{a}}$ \\
\hline
\end{tabular}

Cohort A: Pre-change outpatient follow-up; Cohort B: Post-change outpatient follow-up + PTFU;

Cohort B1: Post-change outpatient follow-up only; Cohort B2: Post-change PTFU only

${ }^{\mathrm{a}}$ Unpaired $\mathrm{t}$ test

${ }^{\mathrm{b}}$ Chi-square test

Abbreviations: $P T F U=$ patient-triggered follow-up; $C$ hemo = chemotherapy; $R T=$ Radiotherapy; $M A=$ microwave ablation;

$P R O M=$ patient reported outcome measurement; $E Q 5 D-5 L=$ Euro-Qol Group health score[worst -0.594 ,best 1$]$; VAS = visual analogue scale[worst 0 100]; $F A C T=$ Functional Assessment of Cancer Treatment; $P W B=$ physical wellbeing subscale[worst 0, best 28]; $S W B=$ social wellbeing[worst 0 , best 28]; $E W B=$ emotional wellbeing[worst 0 , best 24]; $F W B=$ functional wellbeing[worst 0 , best 28]; $C R C s=$ additional colorectal cancer concerns[worst 0 , best 28]; FACT-G = Functional Assessment of Cancer Therapy- General Total QoL score[0 worst, best 108]

studies have evaluated PTFU as an alternative to OPFU, but those evaluating breast follow-up found no difference in QoL, psychological morbidity, [11, 12] or satisfaction [31]. No study has indicated PTFU is less safe than routine OPFU, and a recent 5-year remote surveillance study of surgically treated CRC patients [31] found the approach safe and costeffective. The presence of symptom morbidity interacting adversely with LTCs (over a quarter of patients in this study had two or more) identifies a subgroup of patients where nurse-led risk assessment could lead to tailored follow-up plans for survivors who may require more active support. This is a key finding; as more services move towards risk-stratified approaches to follow-up care, defining the individual dimensions of supportive care required by all CRC survivors is an essential precursor to relevant supportive care services [36].

After active treatment, survivors can experience sudden and unforeseen anxiety and distress in the transition to follow-up care [37]. Evidence from a survey of patient-reported outcomes suggests information and preparation for follow-up is limited, a qualitative analysis of comments leading researchers to conclude "patients being cut adrift" by the health system after active treatment [38]. An important and positive finding from our study demonstrates that most patients were reassured by their follow-up, found their care either exceeded or met their expectations, and reported excellent or very good quality of care.

More PTFU than OPFU patients found their care to be acceptable. PTFU provided ingredients evidenced to be very important to patients: convenience, tailored information [39], reassurance through a formal process of quick access to specialist advice and tests [37], continuity of care-provider (CNS) [37], and a trusting relationship with specialist nurses [39]. Data available from the study can be utilised to modify and improve the service and address the needs of the small subgroup who found aspects of their care not acceptable. 
Table 3 Regressions at T2

\begin{tabular}{|c|c|c|c|c|c|}
\hline Outcome at T2 [range] & Constant & $\mathrm{B}^{\mathrm{a}}$ & Predictor & $P$ - value & $\mathrm{R}^{2}$ \\
\hline EQ5D-5 L [-0.594 to 1 (best)] & 0.877 & $-0.066^{\mathrm{b}}$ & $\begin{array}{l}\text { Number of longstanding conditions } \\
\text { including 'other' at T2 }\end{array}$ & $<0.001$ & 0.121 \\
\hline \multirow[t]{3}{*}{ FACT-G at T2 [0 to 108 (best)] } & \multirow[t]{3}{*}{95.225} & $-5.266^{\mathrm{c}}$ & $\begin{array}{l}\text { Number of longstanding conditions } \\
\text { including 'other' at T2 }\end{array}$ & $<0.001$ & \multirow[t]{3}{*}{0.168} \\
\hline & & $+13.226^{\mathrm{d}}$ & Had heart disease at $\mathrm{T} 2$ & 0.008 & \\
\hline & & $-5.741^{\mathrm{e}}$ & Had chemotherapy by $\mathrm{T} 0$ & 0.047 & \\
\hline \multirow[t]{3}{*}{ Colorectal Cancer Concerns [0 to 28(best)] } & \multirow[t]{3}{*}{24.227} & $-3.197^{\mathrm{f}}$ & In work at $\mathrm{T} 2$ & 0.001 & \multirow[t]{3}{*}{0.188} \\
\hline & & $-1.240^{\mathrm{g}}$ & $\begin{array}{l}\text { Number of longstanding conditions } \\
\text { including 'other' at T2 }\end{array}$ & 0.003 & \\
\hline & & $+3.637^{\mathrm{h}}$ & Had heart disease at $\mathrm{T} 2$ & 0.009 & \\
\hline
\end{tabular}

${ }^{a}$ Unstandardised coefficient

${ }^{\mathrm{b}}$ Each longstanding condition reduces EQ5D score by 0.066 , so 3 longstanding conditions, score falls (worse by 0.2 points)

${ }^{\mathrm{c}}$ Each longstanding condition reduces FACT-G score by 5.266 points, so 3

longstanding conditions, score falls (worse by 15.8 points)

${ }^{\mathrm{d}}$ If heart disease present, FACT-G score rises (better by 13.226 points)

${ }^{\mathrm{e}}$ If had chemotherapy, FACT-G score falls (worse by 5.741 points)

${ }^{\mathrm{f}}$ If in work, colorectal cancer concerns score falls (worse by 3.197 points)

${ }^{g}$ Each longstanding condition reduces colorectal cancer concerns score by 1.24

points, so 3 longstanding conditions, score falls (worse by 3.72 points)

${ }^{\mathrm{h}}$ If heart disease present, FACT-G score rises (better by 3.637 points)

EQ5D-5 L EurolQol health index; FACT-G functional assessment of cancer therapy -general

Expectations of care were met or exceeded for all patients in PTFU but were not realised by a small number of patients in OPFU. This may reflect that, in contrast to PTFU patients who attend a self-management workshop, those in OPFU receive no formal explanation of the follow up processes. Also, OPFU patients are more troubled by symptoms. Routine clinic check-ups and tests intended to allay anxiety, provide only temporary reassurance for some, who then have an anxious wait for their next clinic visit [37]. Moreover, support for ongoing symptoms, and concerns after treatment, may have been lacking [40].
The present study responded to the need to redesign existing services to improve patient experience and address the rising demand for follow-up that puts limited resources under pressure. Exploring impact on resource use and costs is important when redesigning follow-up care models [41]. After one year, released clinical capacity in the study setting enabled the establishment of a nurse-led service for patients with complex needs. PTFU was, however, slightly more expensive than OPFU in the first year, largely due to a self-management workshop and costs associated with staff organising remote surveillance. If fixed costs of training and IT software had been included in the

Table 4 Patient reported quality, and expectations of follow-up care at T2: Cohort A, B1, and B2

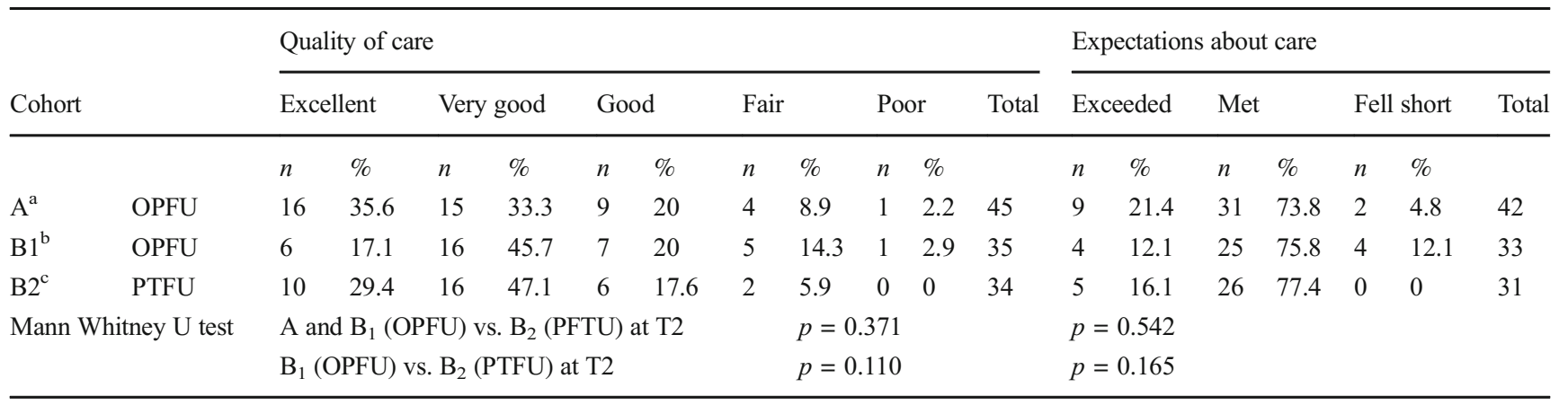

\footnotetext{
${ }^{a}$ Pre-service change outpatient follow-up

${ }^{\mathrm{b}}$ Post-service change outpatient follow-up

${ }^{\mathrm{c}}$ Post-service change patient triggered follow-up
} 
calculations, excess costs would have been greater. Economies of scale in the delivery of the workshop may be realised in the future as the service reaches capacity. Taking a five-year perspective, up to ten outpatient appointments could be saved by PTFU. In addition to health care system savings, PTFU reduces time and financial costs for patients associated with having a cancer diagnosis [42].

The strengths of the study are its prospective longitudinal design and use of validated tools for comparing QoL [19-22] in post-treatment CRC survivors experiencing novel and standard follow-up care. Important insights on stratification of patients post- treatment and perceptions of care quality were provided which if addressed should improve follow-up in the future. The new PTFU model was designed with clinicians, and delivered by these same clinicians. It preserved clinical judgement about the best follow-up model for their patient, reflecting a real world embedded service evaluation [43].

The study has several limitations. Data collection of the postchange cohort was started soon after PTFU was commenced in order to achieve planned recruitment within the study period. Clinicians made the decision to enrol patients in PTFU, but readiness to change was limited and willingness evolved with time. This had an impact on the size of this group. It also meant that patients in OPFU were generally sicker, making it difficult to interpret the differences in patient and health service outcomes. Transfer of patients from OPFU to PTFU at differing times resulted in contamination of the PTFU group. In the analysis, any patient who entered PTFU before $\mathrm{T} 2$ was considered to be in the PTFU group but this masked considerable variability in timing. Also, delayed distribution and return of questionnaires meant some assessments deviated from the planned schedule of data collection. Data collection was curtailed due to time pressures, therefore numbers of patients were not sent follow-up questionnaires at T1/2/3. The decision to undertake the analysis at T2 ( 8 months post final treatment), prevented comparison of the 12-months outcomes for the two models was pragmatic, in that loss to follow-up gradually reduced group sizes. Attrition at T2, particularly in group B was high due to recurrence or metastatic disease.

In conclusion, enrolment of patients in PTFU is largely a clinical decision determined by the pace of patient recovery. This model of PTFU, introduced by a self-management workshop [44], was found acceptable to patients, and will allow low, and some moderate risk patients to undergo five-year surveillance without routine clinic attendance but with access to clinical input if necessary. Cancer specific QoL and HRQoL outcomes were influenced by side effects of treatments and the presence of LTCs, rather than the follow-up model, and should lead to the promotion of targeting tailored supportive care for those at risk.

Acknowledgements Funding for the study was provided by the National Cancer Survivorship Initiative (Department of Health England,
Macmillan Cancer Support). We are grateful to all patients who took part in the evaluation by completing questionnaires. The authors thank Ginny Cranshaw, Linda Sayburn, Caroline Millier, Angie Smith, Sally Backhouse and all the Colorectal Clinical Team, for support during the evaluation. In addition, we thank Dave McHattie, Anna Lynall, and the cancer survivors who contributed to the development and delivery of the self-management workshop. Thanks are also given to the anonymous reviewers whose comments improved the paper.

\section{Compliance with ethical standards}

Conflict of interest The authors declare that they have no competing interest.

Open Access This article is distributed under the terms of the Creative Commons Attribution-NonCommercial 4.0 International License (http:// creativecommons.org/licenses/by-nc/4.0/), which permits any noncommercial use, distribution, and reproduction in any medium, provided you give appropriate credit to the original author(s) and the source, provide a link to the Creative Commons license, and indicate if changes were made.

\section{References}

1. Cancer Research UK (2014) Cancer Incidence in the UK in 2011

2. Maddams SJ, Utley M, Moller H (2012) Projections of cancer prevalence in the United Kingdom 2010-2040. Br J Cancer 107:11951202

3. Al Chalabi H, O'Riordan JM, Richardson A, Flanner D, O'Connor K, Stuart C, Larkin J, McCormick P, Mehigan B (2014) Six-year experience of a nurse-led colorectal cancer follow-up clinic. Surgery Research and Practice:1-5. doi:10.1155/2014/368060

4. McFarlane K, Dixon L, Wakeman CJ, Robertson TW, Eglinton TW, Frizelle FA (2011) The process and outcomes of a nurse-led colorectal cancer follow-up clinic. Col Dis 14:e245-e249. doi:10. 1111/j.1463-1318.2011.02923.x

5. Beaver K, Campbell M, Williamson S, Procter D, Sheridan J, Heath J, Susnerwala S (2012) An exploratory randomised controlled trial comparing telephone and hospital follow-up after treatment for colorectal cancer. Col Dis 14:1201-1209. doi:10.1111/j.1463-1318. 2012.02936.x

6. Cusack M, Taylor C (2010) A literature review of the potential of telephone follow-up in colorectal cancer. J of Clin Nurs 19:2394 2405. doi:10.1111/j.1365-2702.2010.03253.x

7. Jeffery M, Hickey BE, Hider PN (2008) Follow-up strategies for patients treated for non-metastatic colorectal cancer (Cochran review). 2008. The Cochrane Collaboration, John Wiley \& Sons, Ltd, New Jersey

8. Primrose JN, Perera R, Gray A, Rose P, Fuller A, Corkhill A, George S, Mant D (2014) FACS trial investigators. Effect of 3 to 5 years of scheduled CEA and CT follow-up to detect recurrence of colorectal cancer: the FACS randomised clinical trial. JAMA 311(3):263-270. doi:10.1001/jama2013.285718

9. Figueredo A, Rumble RB, Maroun J, Earle CC, Cummings B, McLeod R, Zuraw L, Zwaal C (2003) And members of the gastrointestinal cancer disease site Group of Cancer Care Ontario's program in evidence-based care follow-up of patients with curatively resected colorectal cancer: a practice guideline. BMC Cancer 3(26):1-13

10. Grunfeld E, Levine MN, Julian JA, Coyle D, Szechtman B, Mirsky D, Verma S, Dent S, Sawka C, Pritchard KI, Ginsburg D, Wood ML, Whelan T (2006) Randomised trial of long-term follow-up for early stage breast cancer: a comparison of family physician versus specialist care. J Clin Oncol 24:848-855 
11. Koinberg IL, Fridlund B, Engholm GB, Holmberg L (2004) Nurseled follow-up on demand or by a physician after breast cancer surgery: a randomised study. Eur J Oncol Nurs 8:109-117

12. Sheppard C, Higgins B, Wise M, Yiangou C, Dubois D, Kilburn S (2009) Breast cancer follow-up: a randomised controlled trial comparing point of need access versus routine 6-monthly clinical review. Eur J Oncol Nurs 13:2-8. doi:10.1016/j.ejon.2008.11.005

13. Macmillan Cancer Support and Mouchel (2014) Specialist adult cancer nurses in England: A census of the specialist adult cancer nursing workforce in the UK

14. Teagle A, Gilbert DC (2014) Remote follow-up strategies after cancer treatment: a lot of opportunities. Clin Oncol (R Coll Radiol) 26(10):622-624. doi:10.1016/j.clon.2014.05.009

15. Martin F, Turner A, Bourne C, Batehup L (2013) Development and qualitative evaluation of a self-management workshop for testicular cancer survivor - initiated follow-up. Oncol Nurs Forum 40:E14 E23. doi:10.1188/13.x

16. National Institute for Health and Care Excellence (2014) Clinical guideline 131: the diagnosis and management of colorectal cancer Available at: guidance.nice.org.uk/ $\operatorname{cg} 131: 2011$

17. Jorgensen ML, Young JM, Solomon MJ (2015) Optimal delivery of colorectal cancer care: improving patient outcomes. Patient Related Outcome Measures 5(6):127-138

18. Office for National Statistics. Index of Multiple Deprivation.https/ www.gov.uk/government/collections/English-indices-of-depr. Accessed 6 June 2015

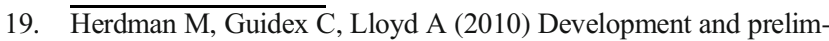
inary testing of the new five level version of EQ-5D (EQ-5D-5 L). Qual Life Res 20:1727-1736

20. EuroQol Group (2009) The EQ-5D-5 L UK (English) v.2. EuroQol Group EQ-5D TM

21. Cella DF, Tulsky DS, Gray G, Sarafian B, Lloyd S, Linn E, Bonomi A, Siberman M, Yellen SB, Winicour P, Brannon J, Eckberg K, Purl S, Blendowski C, Goodman M, Barnicle M, Stewart I, McHale M, Bomnomi P, Kaplan E, Taylor S, Harris J (1993) The functional assessment of cancer therapy (FACT) scale: development and validation of the general measure. J Clin Oncol 11(3):570-579

22. Ward WL, Hahn EA, Mo F, Hernandez L, Tulsky DS, Cella D (1999) Reliability and validity of the functional assessment of cancer therapy-colorectal (FACT-C) quality of life instrument. Qual Life Res 3:181-195

23. Montgomery DA, Krupa K, Cooke TG (2007) Alternative methods of follow-up in breast cancer: a systematic review of the literature. Br J Cancer 96:1625-1632. doi:10.1038/sj.bjc.6603771

24. Rostock M, Nauman J, Guethlin C, Guenther L Bartsch HH, Walach H (2011) Classical homeopathy in the treatment of cancer patients - a prospective observational study of two independent cohorts. BMC Cancer 2011; http://www.biomedicalcentral.com/ 1471-2407/11/19. Accessed 23 July 2015

25. Gray NM, Hall SJ, Brown S, Macleod U, Mitchell E, Lee AJ, Johnson M, Wyke S, Samuel L, Weller D, Campbell NC (2011) Modifiable and fixed factors predicting quality of life in people with colorectal cancer. B J Canc 104:1697-1703

26. Knowles G, Sherwood L, Dunlop MG, Dean G, Jodrell D, McLean C, Preston E (2007) Developing and piloting a nurse-led model of follow-up in the multidisciplinary management of colorectal cancer. Eur J Onc Nurs 11:212-223

27. Steginga SK, Lynch BM, Hawkes A, Aitken J (2009) antecedents of domain-specific quality of life after colorectal cancer. Psychooncol 18:216-220. doi:10.1002/pon.1388
28. Curtis L. Unit Costs of Health and Social Care (2013) http://pssru. ac.uk/project-pages/unit-costs/2013/. Kent: PSSRU. Accessed 20 February 2016

29. Beecham JK, Knapp MRJ (2001) In: Thornicroft G, Brewin C, Wing JK (eds) Costing psychiatric interventions, in measuring mental health needs. Gaskell, London, pp 200-224

30. NHS Improvement Cancer (2012). Adult Survivorship from concept to innovation http://www.ncsi.org.uk/wp-content/uploads/ Concept to_Innovation.pdf. Accessed 6 June 2015

31. Siddika A, Tolia-Shah D, Pearson TE, Richardson NGB, Ross AHML (2015) Remote surveillance after colorectal cancer surgery: an effective alternative to standard clinic-based follow-up. Col Dis 17:870-875. doi:10.1111/codi.12970

32. Frew G, Smith A, Zutshi B, Young N, Aggarwal A, Jones P, Kockelbergh R, Richards M, Maher EJ (2010) Results of a quantitative survey to explore both perceptions of the purpose of followup and preferences for methods of follow-up delivery among service users, primary care practitioners and specialist clinicians after cancer treatment. Clin Oncol (R Coll Radio) 22:874-884. doi:10. 1016/j.clon.2010.06.008

33. Lewis C, Xun P, He K (2015) Effects of adjuvant chemotherapy on recurrence, survival, and quality of life in stage II colon cancer patients: a 24-month follow-up. Support Care Cancer. doi:10. 1007/s00520-015-2931-2

34. Marventano S, Joao Forjaz M, Grosso G, Mistretta A, Giorgianni G, Platania A, Gangi S, Basile F, Biondi A (2013) Health related quality of life in colorectal cancer patients: state of the art. BMC Surg 13(Suppl 2):S15

35. Dalal HM, Doherty PD (2015) Cardiac rehabilitation. BMJ 351. doi:10.1136/bmj.h50000

36. Chubak J, Tuzzio L, Hsu C, Alfano CM, Rabin BA, Hornbrook MC (2012) Providing care for cancer survivors in integrated health care delivery systems: practices, challenges, and research opportunities. J Oncol Pract 8(3):184-189

37. Lewis RA, Neal RD, Hendry M, France D, Williams NH, Russell D (2009) Patients' and healthcare professionals' views of cancer follow-up: systematic review. Br J Gen Prac July; e248-e259

38. Corner J, Wagland R, Glaser A, Richards M (2013) Qualitative analysis of patients' feedback from a PROMs survey of cancer patients in England. BMJ Open 3:e002316

39. Williamson S, Chalmers K, Beaver K (2015) Patient experience of nurse-led follow-up following treatment for colorectal cancer. Eur Jour of Oncol Nursing 19:237-243. doi:10.1016/j.ejon.2014.11.006

40. Cockle-Hearne J, Charnay-Sonnek F, Denis L, Fairbanks HE, Kelly D, Kav S, Leonard K, van Muilekom E, Fernandez-Ortega P, Jensen BT, Faithful S (2013) The impact of supportive nursing care on the needs of men with prostate cancer: a study across seven European countries. B J Canc 109:2121-2130. doi:10.1038/bjc.2013.568

41. Leeuw J, Larsson M (2013) Nurse-led follow-up care for cancer patients: what is known and what is needed. Support Care Cancer 21:2643-2649. doi:10.1007/s00520-013-1892-6

42. Macmillan Cancer Support (2014) Cancers Hidden Price Tag. Macmillan Cancer Support

43. Pawson R, Tilley N (2009) Realist Evaluation. In: Otto H, Polutta A, Ziegler H(eds) Evidence based practice. Modernising the knowledge base of social work? Barbara Budrich, Framingham Hill, MI

44. Bourne C, Martin F, Turner A, McHattie D, Batehup L (2012) Defining and Piloting a Self-Management Workshop for Colorectal Cancer Survivors. British Psychosocial Oncology Society Conference, January 19th 2012 